\title{
Analisa Metode MGR Untuk Mendeteksi Keaslian Citra Digital
}

\author{
Rani Aflisa Zay*, Mesran \\ Program Studi Teknik Informatika, Universitas Budi Darma, Medan, Indonesia \\ Email: 1,*Raniaflisazay@gmail.com, ${ }^{2}$ mesran.skom.mkom@gmail.com
}

\begin{abstract}
Abstrak-Pengolahan citra digital merupakan bagian penting yang mendasari berbagai aplikasi nyata, seperti pengenalan pola, penginderaan jarak jauh melalui satelit atau pesawat udara, dan machine vision. Pada pengenalan pola, pengolahan citra digital antar lain berperan memisahkan objek dari latar belakang secara otomatis. Hampir semua penerapan teknologi informasi menggunakan kriptografi sebagai alat untuk menjamin keamanan dan kerahasiaan data atau informasi. Karena itu kriptografi menjadi suatu ilmu yang berkembang pesat dan dalam waktu singkat banyak muncul algoritma-algoritma baru yang dianggap lebih unggul daripada algoritma pendahulunya. Untuk melihat keaslian citra digital kita menggunkan algoritma MGR. Fungsi hash MGR yang didasarkan pada keamanan desainnya. Diamankan dari serangan multicollision, serangan titik tetap, panjang serangan ekstensi dan serangan menggiring dan memberikan efisien yang lebih baik (tiga kali lebih cepat) dari pada GOST-R. AES seperti blok cipher telah digunakan dalam mendesain kompresi. Fungsi MGR karena AES adalah salah satu blok yang paling efisien dan aman sandi dan telah dievaluasi selama lebih dari 12 tahun.
\end{abstract}

Kata Kunci: Kriptografi; MGR; Pengolahan Citra

Abstract-Digital image processing is an important part that underlies various real applications, such as pattern recognition, remote sensing via satellite or aircraft, and machine vision. In pattern recognition, digital image processing plays a role in separating objects from the background automatically. Almost all applications of information technology use cryptography as a tool to ensure the security and confidentiality of data or information. Because of this, cryptography has become a rapidly growing science and in a short time many new algorithms have emerged which are considered superior to their predecessor algorithms. To see the authenticity of digital images we use the MGR algorithm. MGR hash function based on its design security. Protected against multicollision attacks, fixed point attacks, extension attack lengths and herd attacks and provides better efficiency (three times faster) than GOST-R. AES such as block ciphers have been used in compression design. The MGR function due to AES is one of the most efficient and cipher-secure blocks and has been evaluated for more than 12 years.

Keywords: Cryptography; MGR; Image Processing

\section{PENDAHULUAN}

Citra digital sangat populer pada masa sekarang. Banyak peralatan elektronik, misalkan scanner, kamera digital, mikroskop digital, dan fingerprint reader (pembaca sidik jari) yang menghasilkan citra digital. Pengolahan citra digital bertujuan untuk melakukan suatu proses untuk mendapatkan informasi atau deskripsi objek yang terkandung pada citra. Dalam beberapa tahun terakhir pengumpulan dan pengolahan data berbentuk citra berkembang sangat pesat. Kecanggihan teknologi pada saat ini memang tidak bias diragukan lagi. Untuk mendapatkan informasi secara tepat dan praktis tidaklah menjadi hal yang sulit.

Citra Digital merupakan suatu representatif dari citra yang akan diambil oleh sebuah mesin dengan berbagai bentuk pendekatan didasarkan sampling atau kuantisasi. Sampling ini terbagi menjadi dua yaitu Sampling besar menyatakan bahwa dimana kotak-kotaknya yang akan disusun secara baris dan kolom. Sedangkan Sampling besar kecil juga menyatakan dimana ukuran suatu pixelnya (titik) pada citra. Kuatitasi juga menyatakan bahwa besar nilai tingkat kecerahan dinyatakan dalam sebuah nilai tingkat keabuan (grayscale) yang sesuai dengan jumlah banyaknya bit biner digunakan oleh mesin.

Citra (image) sebagai salah satunya juga bertujuan untuk pokok bagi suatu organisasi atau perusahaan. Akan tetapi citra mempunyai karakteristik yang wujudnya dapat dirasakan dari penilaian, baik itu semacam tanda respek dan rasa hormat dari publik yang ada disekelilingnya atau dan masyarakat luas terhadap organiasi atau perusahaan tersebut dapat dilihat sebagai sebuah badan usaha yang dipercaya, profesional, dan dapat diandalkan dalam pembentukan pelayanan yang baik. Disaat ini kasus manipulasi merusak foto/ image bukanlah kasus yang baru selama beberapa akhir. Image yang dirusak muncul dengan frekuensi dan kecanggihan, pengembangan perangkat lunak pengolah image digital yang semakin canggih memudahkan untuk membuat pemalsuan image dari suatu atau bebarapa image tanpa meninggalkan petunjuk yang jelas. Image pada citra digital dibuat atau diedit dengan mudah bahkan tanpa meninggalkan petunjuk visual oleh penggunanya, seperti pada aplikasi PhotoScape dan Adobe Photoshop. Kemudahan dalam membuat dan merubah suatu citra dapat merusak kredibitas keaslian citra digital dalam berbagai aspek, sehingga rawan digunakan untuk tindak kejahatan karena perubahan image pada citra digital dapat merubah informasi yang disampaikan berbeda. Bidang ilmu forensik citra digital akan membantu para penegak hukum, intelijen, investigasi swasta, dan media. Semakin majunya teknologi image pada saat ini mengangkat isu-isu dan tantangan dalam menentukan keaslian image pada citra digital. Forensik merupakan ilmiah pada bidang penelitian yang bertujuan untuk mendapatkan fakta-fakta pembuktian dalam menentukan keaslian citra digital.

Menyajikan versi Modifled GOST-R (MGR-Hash) desain yang dimodifikasi didasarkan pada konstruksi pipa lebar yang juga merupakan Merkle-Damgard yang dimodifikasi konstruksi. MGR lebih aman dan tiga kali lebih cepat. Mgr ( Modifled GOST-R) dapat memiliki aplikasi luas di dunia digital. Karena panjang variabelnya output (panjang antara 256bit hingga 512-bit), dapat digunakan sebagai pseudorandom generator dan untuk menutupin. Ini dapat digunakan dalam 
tanda tangan digital dan kunci publik kriptografi. Ini dapat memainkan peran utama dalam derivasi kunci untuk cipher blok dan stream cipher[1].

Dari paparan diatas, diperlukan sebuah sistem yang mampu melakukan pembuktian keaslian citra digital. Metode tersebut adalah dengan menggunakan teknik MGR untuk mempermudah keaslian citra bagi instansi.

\subsection{Pengolahan Citra}

\section{METODOLOGI PENELITIAN}

Pengolahan citra digital merupakan bagian penting yang mendasari berbagai aplikasi nyata, seperti pengenalan pola, penginderaan jarak jauh melalui satelit atau pesawat udara, dan machine vision. Pada pengenalan pola, pengolahan citra digital antar lain berperan memisahkan objek dari latar belakang secara otomatis. Selanjutnya, objek akan diproses oleh pengklasifikasi pola. Pada machine vision (sistem yang dapat "melihat" dan "memahami" yang dilihatnya), pengolahan citra berperan untuk mengenali bentuk-bentuk khusu yang dilihat oleh mesin. Penggunaan kamera pemantau ruangan merupakan contoh bagian aplikasi pemrosesan citra. Perubahan gerakan yang ditangkap melalui citra dapat menjadi dasar untuk melakukan pelaporan situasi yang terekam [1].

\subsection{Citra}

\subsubsection{Citra Berwarna}

Citra berwarna, atau biasa dinamakan citra RGB, merupakan jenis citra yang menyajikan warna dalam bentuk komponen R (merah), G (hijau), B (biru). Setiap komponen warna menggunakan delapan bit (nilainya berkisar antara 0 sampai dengan 255). Dengan demikian, kemungkinan warna yang dapat disajikan mencapai 255 x 255 x 255 atau 16.581 .375 warna. Tabel 2.1 menunjukan contoh warna dan nilai R, G, B [1].

Tabel 1. Warna dan nilai penyusunan warna

\begin{tabular}{cccc}
\hline Warna & R & G & B \\
\hline Merah & 255 & 0 & 0 \\
Hijau & 0 & 255 & 0 \\
Biru & 0 & 0 & 255 \\
Hitam & 0 & 0 & 0 \\
Putih & 255 & 255 & 255 \\
Kuning & 0 & 255 & 255 \\
\hline
\end{tabular}

\subsubsection{Citra Biner}

Citra biner adalah citra dengan setiap piksel hanya dinyatakan dengan sebuah nilai dari dua kemungkinan (yaitu nilai 0 dan 1). Nilai 0 menyatakan warna hitam dan nilai 1 menyatakan warna putih. Citra jenis ini banyak dipakai dalam pemrosesan cita, misalkan untuk kepentingan memperoleh tepi bentuk suatu objek [2].

\subsubsection{Deteksi Tepi}

Tujuan operasi deteksi tepi adalah meningkatkan penampakan garis batas suatu daerah atau objek di dalam citra. Operator gradien pertama yang digunakan untuk mendeteksi tepi di dalam citra, yaitu operator gradien selisih terpusat, operator Sobel, operator Prewitt, operator Roberts, operator Canny [2].

\subsubsection{Citra Digital}

Citra digital merupakan sebuah larik (array) yang berisi nilai-nilai real maupun komplek yang direpresentasikan dengan deretan bit tertentu. Suatu citra dapat didefinisikan sebagai fungsi $\mathrm{f}(\mathrm{x}, \mathrm{y})$ berukuran M baris dan N kolom, dengan x dan y adalah koordinat spasial, dan amplitudo f di titik koordinat $(x, y)$ dinamakan intentitas atau tingkat keabuan dari citra pada titik tersebut. Apabila nilai $\mathrm{x}, \mathrm{y}$, dan nilai amplitudo f secara keseluruhan berhingga (finite) dan bernilai diskrit maka dapat dikatakan bahwa citra tersebut adalah citra digital. Nilai pada suatu irisan antara baris dan kolom (pada posisi x,y) disebut dengan picture elements, image elements, pels, atau pixels. Istilah terakhir (pixel) paling sering digunakan pada citra digital [1].

\subsection{Analisa}

Analisa merupakan kegiatan menguraikan atau memecahkan suatu unit menjadi unit terkecil yang terbagi-bagi.

Bahwapengertian analisis adalah sebuah aktivitas, proses dan kegiatan yang saling terhubung untuk memecahkan agar lebih detail kemudian digabungkan kembali supaya bisa ditarik kesimpulan yang tepat. Dalam menganalisis, gambaran pola-pola yang ada didalam data harus konsisten. Dengan begitu, hasil analisa dapat diterjemahkan dan dipelajari dengan mudah, bermakna, dan singkat [3]. 


\section{TIN: Terapan Informatika Nusantara}

Vol 2, No 8, Januari 2022, Hal 492-500

ISSN 2722-7987 (Media Online)

Website https://ejurnal.seminar-id.com/index.php/tin

DOI 10.47065/tin.v2i8.1029

\subsection{Kriptografi}

Kriptografi telah menjadi bagian penting dalam dunia teknologi informasi, terutama dalam bidang komputer.Hampir semua penerapan teknologi informasi menggunakan kriptografi sebagai alat untuk menjamin keamanan dan kerahasiaan data atau informasi. Karena itu kriptografi menjadi suatu ilmu yang berkembang pesat dan dalam waktu singkat banyak muncul algoritma-algoritma baru yang dianggap lebih unggul daripada algoritma pendahulunya [4].

\subsection{Metode MGR}

Fungsi hash MGR merupakan dapat memberikan output dari panjang variabel, yaitu setiap panjang di antara 256-bit ke 512-bit. Kita dapat mencapai panjang apa pun dari mencerna antara 256 hingga 512-bit, dikelipatan 32-bit. Untuk hash digest panjang yang berbeda, kita hanya perlu memperbaiki tetapi berbeda nilai awal yang konstan. Di sini, kita akan memiliki hash digest 256-bit. Pesannya adalah pertama kali diisi sehingga menjadi kelipatan 1024-bit dan register awal 1024-bit terdiri dari nilai awal h 0 dari 512-bit bersama dengan konstanta (penghitung) dari 512-bit diambil sebagai input dari delapan AES-128 secara paralel. Karena, ini adalah hash pipa ganda, karenanya variabel rantai adalah setengah dari panjang blok yaitu 512-bit. Delapan simultan AES bekerja pada input h 0 dan blok pesan. Setelah putaran pertama AES itu output 1024-bit dibiarkan diputar oleh 96-bit untuk memastikan difusi dengan setiap putaran AES. Setiap putaran cipher blok memang merupakan putaran AES; ada kebutuhan Kunci 1024-bit (jadwal) untuk setiap putaran dan itu dilakukan dengan menggunakan putaran (ditentukan sebelumnya) konstanta sebagai kunci dan pesan diperbarui sebagai blok pesan [5].

\section{HASIL DAN PEMBAHASAN}

Analisa merupakan proses awal yang harus dilakukan untuk menentukan permasalahan yang sedang dihadapi. Dengan adanya analisis sistem, sistem yang dirancang akan lebih baik dan memudahkan pengembangan sistem dalam perbaikan apabila pada kemudian hari ditemukan kesalahan atau kekurangan. Tahap ini adalah tahap yang sangat penting, karena proses analisa yang kurang akurat akan menyebabkan hasil yang tidak sesuai dengan diharapkan. Jadi proses ini harus benar-benar sesuai dengan keinginan para pengguna agar hasilnya dapat memuaskan pengguna. Masalah yang dianaliasa adalah untuk mendeteksi keaslian citra digital menggunakan metoge MGR (Modified GOST-R). Analisa ini bertujuan untuk menganalisa citra dan diharapkan menghasilkan analisa citra yang baik.

\subsection{Proses kerja algoritma MGR (Modified GOST-R)}

Dalam analisa citra yang ingin di proses adalah citra berwarna, dimana citra asli awalnya memiliki nilai pixel 1200x1600.

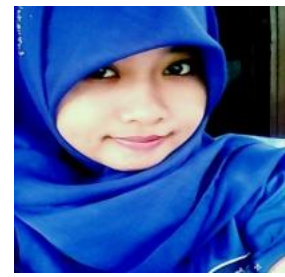

Gambar 1. Citra Asli

Karena nilai pixel gambarnya besar maka dimasukkan kedalam sebuah matriks yang ordo sama dengan ukuran gambar yaitu $6 x 6$ pixel. Berikut ini nilai pixel dari gambar $6 \times 6$.

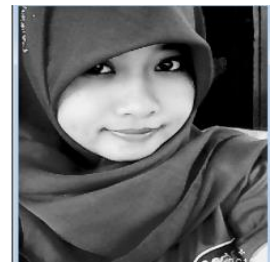

Gambar 2. Citra Grayscale

Mencari nilai pixel 6x6 mengunakan aplikasi MATLAB Hasil setelah resolusi pixel 6x6

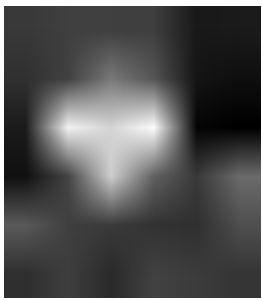




\section{TIN: Terapan Informatika Nusantara}

Vol 2, No 8, Januari 2022, Hal 492-500

ISSN 2722-7987 (Media Online)

Website https://ejurnal.seminar-id.com/index.php/tin

DOI 10.47065/tin.v2i8.1029

\section{Gambar 3. Resolusi Pixel}

\subsection{Pengolahan dalam blok pesan berukuran 512 bit}

Semua bit plainteks yang berjumlah 512 bit dibagi menjadi 16 blok yang mana setiap satu blok berisi 32 bit bagian. Berikut adalah 16 blok tersebut :

$\begin{array}{ll}\mathrm{M}_{0} & =00111010010000110011110001000001 \\ \mathrm{M}_{1} & =00100101000101000011011000111010 \\ \mathrm{M}_{2} & =01111101010101010000101000010010 \\ \mathrm{M}_{3} & =00001110111110111110001111101101 \\ \mathrm{M}_{4} & =10110100011000010010111101101011 \\ \mathrm{M}_{5} & =01001110001111000101000101010001 \\ \mathrm{M}_{6} & =00110000010100010011010101001000 \\ \mathrm{M}_{7} & =00000000000000000000000000000000 \\ \mathrm{M}_{8} & =00000000000000000000000000000000 \\ \mathrm{M}_{9} & =00000000000000000000000000000000 \\ \mathrm{M}_{10} & =00000000000000000000000000000000 \\ \mathrm{M}_{11} & =00000000000000000000000000000000 \\ \mathrm{M}_{12} & =00000000000000000000000000000000 \\ \mathrm{M}_{13} & =00000000000000000000000000000000 \\ \mathrm{M}_{14} & =00000000000000000000000000000000 \\ \mathrm{M}_{15} & =00000000000000000000000000000000 \\ & \text { Pertama, blok pesan } 32 \text { bit H diturunkan untuk setiap langkah i dari i blok pesan } 512 \text { bit M menggunakan jadwal }\end{array}$ pesan .

$\mathrm{H}_{0} \quad=00111010010000110011110001000001$

$\mathrm{H}_{1} \quad=00100101000101000011011000111010$

$\mathrm{H}_{2}=01111101010101010000101000010010$

$\mathrm{H}_{3}=00001110111110111110001111101101$

$\mathrm{H}_{4}=10110100011000010010111101101011$

$\mathrm{H}_{5}=01001110001111000101000101010001$

$\mathrm{H}_{6}=00110000010100010011010101001000$

$\mathrm{H}_{7}=00000000000000000000000000000000$

$\mathrm{H}_{8}=00000000000000000000000000000000$

$\mathrm{H}_{9}=00000000000000000000000000000000$

$\mathrm{H}_{10}=00000000000000000000000000000000$

$\mathrm{H}_{11}=00000000000000000000000000000000$

$\mathrm{H}_{12}=00000000000000000000000000000000$

$\mathrm{H}_{13}=00000000000000000000000000000000$

$\mathrm{H}_{14}=00000000000000000000000000000000$

$\mathrm{H}_{15}=00000000000000000000000000000000$

rumus berikut:

Untuk $\mathrm{i}<16, \mathrm{H}$ adalah $\mathrm{i}$ hanya $32 \mathrm{~h}$ diatas. Pada saat $\mathrm{i} \geq 16$ atau untuk $\mathrm{H}_{16}, \mathrm{H}$ diturunkan secara rekursif dengan

$\mathrm{H}_{\mathrm{i}}=\left(\mathrm{H}_{\mathrm{i}-16} \oplus \mathrm{H}_{\mathrm{i}-14} \oplus \mathrm{H}_{\mathrm{i}-8} \oplus \mathrm{H}_{\mathrm{i}-3}\right)$

$\mathrm{H}_{16}=\left(\mathrm{H}_{16-16} \oplus \mathrm{H}_{16-14} \oplus \mathrm{H}_{16-8} \oplus \mathrm{H}_{16-3}\right)$

Berarti :

$\mathrm{H}_{\mathrm{i}}=\mathrm{H}_{16-16} \quad=\mathrm{H} 0$

$\mathrm{H}_{\mathrm{i}}=\mathrm{H}_{16-14} \quad=\mathrm{H} 2$

$\mathrm{H}_{\mathrm{i}}=\mathrm{H}_{16-8} \quad=\mathrm{H} 8$

$\mathrm{H}_{\mathrm{i}}=\mathrm{H}_{16-3} \quad=\mathrm{H} 13$

$\mathrm{H}_{\mathrm{i}}=\left(\mathrm{H}_{0} \oplus \mathrm{H}_{2} \oplus \mathrm{H}_{8} \oplus \mathrm{H}_{13}\right)$

\begin{tabular}{l}
$H 0=00111010010000110011110001000001$ \\
$H 2=01111101010101010000101000010010$ \\
$H 8=00000000000000000000000000000000$ \\
$H 13=00000000000000000000000000000000$ \\
\hline$H 16=01000111000101100011011001010011$
\end{tabular}

Untuk $\mathrm{H}_{\mathrm{t}}=\mathrm{H}_{17}$ atau selanjutnya, yaitu :

$$
\mathrm{H}_{17}=\left(\mathrm{H}_{17-15} \oplus \mathrm{H}_{17-13} \oplus \mathrm{H}_{17-7} \oplus \mathrm{H}_{17-2}\right)
$$

dan untuk seperti itu seterusnya.

$\mathrm{H}_{\mathrm{t}} \quad=\left(\mathrm{H}_{2} \oplus \mathrm{H}_{4} \oplus \mathrm{H}_{10} \oplus \mathrm{H}_{15}\right)$ 
Dan hasil $\mathrm{H}_{17}$ setelah dirotasi 1 kali :

$$
\begin{gathered}
H 2=01111101010101010000101000010010 \\
H 4=10110100011000010010111101101011 \\
H 10=00000000000000000000000000000000 \\
H 15=00000000000000000000000000000000 \\
\hline H 17=11001001001101000010010101111001
\end{gathered}
$$

$\mathrm{H}_{17}=11001001001101000010010101111001$

Karena t sebanyak 97 iterasi maka selanjutnya adalah hasil iterasi dan telah mengalami rotasi 1 kali keseluruhannya dari 16 hingga 96 untuk $\mathrm{H}_{\mathrm{t}}$.

$\mathrm{H}_{16}=01000111000101100011011001010011$

$\mathrm{H}_{17}=11001001001101000010010101111001$

$\mathrm{H}_{18}=01001101000001000001101000110010$

$\mathrm{H}_{19}=00110000010100010011010101001000$

$\mathrm{H}_{20}=01000111000101100011011001010011$

$\mathrm{H}_{21}=00110000010100010011010101001000$

$\mathrm{H}_{22}=01000111000101100011011001010011$

$\mathrm{H}_{23}=00000000000000000000000000000000$

$\mathrm{H}_{24}=00001010000100100010110001100001$

$\mathrm{H}_{25}=00001010000100100010110001100001$

$\mathrm{H}_{26}=00000000000000000000000000000000$

$\mathrm{H}_{27}=01001101000001000001101000110010$

$\mathrm{H}_{28}=00001010000100100010110001100001$

$\mathrm{H}_{29}=00001010000100100010110001100001$

$\mathrm{H}_{30}=00001010000100100010110001100001$

$\mathrm{H}_{31}=00001010000100100010110001100001$

$\mathrm{H}_{32}=00001110000100100010110001100001$

$\mathrm{H}_{33}=00000000000000000000000000000000$

$\mathrm{H}_{34}=01000011000110110011011001010011$

$\mathrm{H}_{35}=01101001010110000010111101111010$

$\mathrm{H}_{36}=00000000000000000000000000000000$

$\mathrm{H}_{37}=01000111000101100011011001010011$

$\mathrm{H}_{38}=00101111010011100001100100101001$

$\mathrm{H}_{39}=01000111000101100011011001010011$

$\mathrm{H}_{40}=01001101000001000001101000110010$

$\mathrm{H}_{41}=01101001010110000010111101111010$

$\mathrm{H}_{42}=00101110010011100001100100101001$

$\mathrm{H}_{43}=00000000000000000000000000000000$

$\mathrm{H}_{44}=00101110010011100001100100101001$

$\mathrm{H}_{45}=01101001010110000010111101111010$

$\mathrm{H}_{46}=01101001010110000010111101111010$

$\mathrm{H}_{47}=01101001010110000010111101111010$

$\mathrm{H}_{48}=01101001010110000010111101111010$

$\mathrm{H}_{49}=01101001010110000010111101111010$

$\mathrm{H}_{50}=01000111000101100011011001010011$

$\mathrm{H}_{51}=00101110010011100001100100101001$

$\mathrm{H}_{52}=01101001010110000010111101111010$

$\mathrm{H}_{53}=01101001010110000010111101111010$

$\mathrm{H}_{54}=01000111000101100011011001010011$

$\mathrm{H}_{55}=01101001010110000010111101111010$

$\mathrm{H}_{56}=01101001010110000010111101111010$

$\mathrm{H}_{57}=01000111000101100011011001010011$

$\mathrm{H}_{58}=01000111000101100011011001010011$

$\mathrm{H}_{59}=00000000000000000000000000000000$

$\mathrm{H}_{60}=00101110010011100001100100101001$

$\mathrm{H}_{61}=01000111000101100011011001010011$

$\mathrm{H}_{62}=01000111000101100011011001010011$

$\mathrm{H}_{63}=01000111000101100011011001010011$

$\mathrm{H}_{64}=01000111000101100011011001010011$

$\mathrm{H}_{65}=01000111000101100011011001010011$

$\mathrm{H}_{66}=01000111000101100011011001010011$

$\mathrm{H}_{67}=00000000000000000000000000000000$

$\mathrm{H}_{68}=01101001010110000010111101111010$ 


\section{TIN: Terapan Informatika Nusantara}

Vol 2, No 8, Januari 2022, Hal 492-500

ISSN 2722-7987 (Media Online)

Website https://ejurnal.seminar-id.com/index.php/tin

DOI 10.47065/tin.v2i8.1029

$\mathrm{H}_{69}=01000110000101100011011001010011$

$\mathrm{H}_{70}=01000111000101100011011001010011$

$\mathrm{H}_{71}=01000110000101100011011001010011$

$\mathrm{H}_{72}=01000110000101100011011001010011$

$\mathrm{H}_{73}=01000111000101100011011001010011$

$\mathrm{H}_{74}=01000110000101100011011001010011$

$\mathrm{H}_{75}=00000000000000000000000000000000$

$\mathrm{H}_{76}=00000001000000000000000000000000$

$\mathrm{H}_{77}=01000111000101100011011001010011$

$\mathrm{H}_{78}=01000111000101100011011001010011$

$\mathrm{H}_{79}=01000111000101100011011001010011$

$\mathrm{H}_{80}=01000111000101100011011001010011$

$\mathrm{H}_{81}=01000111000101100011011001010011$

$\mathrm{H}_{82}=00000001000000000000000000000000$

$\mathrm{H}_{83}=01000110000101100011011001010011$

$\mathrm{H}_{84}=01000110000101100011011001010011$

$\mathrm{H}_{85}=00000000000000000000000000000000$

$\mathrm{H}_{86}=00000001000000000000000000000000$

$\mathrm{H}_{87}=00000000000000000000000000000000$

$\mathrm{H}_{88}=00000000000000000000000000000000$

$\mathrm{H}_{89}=00000001000000000000000000000000$

$\mathrm{H}_{90}=01000110000101100011011001010011$

$\mathrm{H}_{91}=00000000000000000000000000000000$

$\mathrm{H}_{92}=00000001000000000000000000000000$

$\mathrm{H}_{93}=00000001000000000000000000000000$

$\mathrm{H}_{94}=00000001000000000000000000000000$

$\mathrm{H}_{95}=00000001000000000000000000000000$

$\mathrm{H}_{96}=00000001000000000000000000000000$

Untuk semua $\mathrm{H}_{\mathrm{t}}$ di atas akan digunakan untuk proses dengan penyangga dan penambah yang telah ditetapkan dalam MGR. Selanjutnya memproses dari persamaan operasi dasar MGR, yaitu :

$a, b, c, d, e \leftarrow\left(\operatorname{CLS}_{5}(a)+f_{t}(b, c, d)+e+H_{t}+K_{t}\right), a, \operatorname{CLS}_{10}(b), c, d$

$\mathrm{a}=\mathrm{A}=67452301$

$\mathrm{b}=\mathrm{B}=$ EFCDAB89

$\mathrm{c}=\mathrm{C}=\mathrm{EFCDAB} 89$

$\mathrm{d}=\mathrm{D}=10325476$

$\mathrm{e}=\mathrm{E} \quad=10325476$

$\mathrm{CLS}_{\mathrm{S}}$ yaitu Circular Left Shift dengan maksud pergeseran atau rotasi bit ke kiri sebanyak s kali, untuk a CLS $_{5}$ berarti sebanyak 5 kali dan untuk b CLS 10 berarti 10 kali. Berikut bentuk CLS :

(a) $=01100111010001010010001100000001$

$\mathrm{CLS}_{5}(\mathrm{a}) \quad=11101000101001000110000000101100$

Tabel 1. Lima penyangga a, b, c, d, dan e

\begin{tabular}{lllll}
\hline $\mathrm{A}$ & $\mathrm{B}$ & $\mathrm{C}$ & $\mathrm{D}$ & $\mathrm{E}$ \\
\hline 67452301 & EFCDAB89 & 98BADCFE & 10325476 & C3D2E1F0 \\
\hline
\end{tabular}

Dikerjakan terlebih dahulu $\mathrm{f}_{\mathrm{t}}(\mathrm{b}, \mathrm{c}, \mathrm{d})$ dengan fungsi logika AND $(\wedge), \mathrm{OR}(\vee), \operatorname{NAND}(\sim)$ : $\mathrm{f}_{\mathrm{t}}(\mathrm{b}, \mathrm{c}, \mathrm{d})$ Putaran 0 hingga $19(\mathrm{~b} \wedge \mathrm{c}) \vee(\sim \mathrm{b} \wedge \mathrm{d})$ :

$(b \wedge c)$

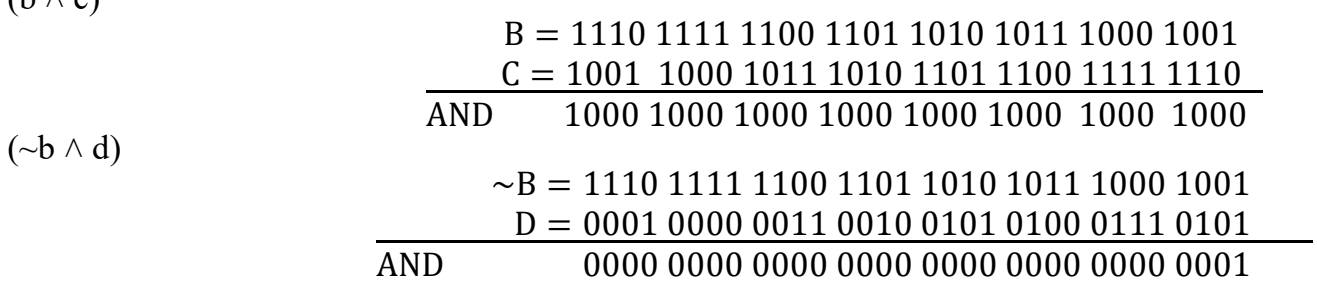

$(b \wedge c) \vee(\sim b \wedge d)$

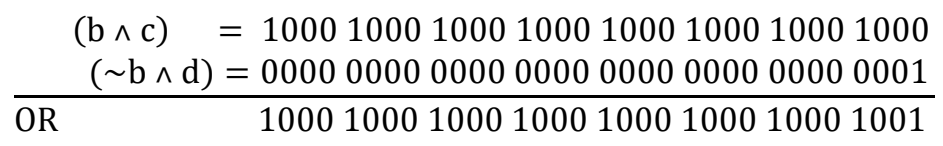




\section{TIN: Terapan Informatika Nusantara}

Vol 2, No 8, Januari 2022, Hal 492-500

ISSN 2722-7987 (Media Online)

Website https://ejurnal.seminar-id.com/index.php/tin

DOI 10.47065/tin.v2i8.1029

Hasil $f_{t}=\quad 10001000100010001000100010001001$

Selanjutnya untuk $\left(\operatorname{CLS}_{5}(\mathrm{a})+\mathrm{f}_{\mathrm{t}}(\mathrm{b}, \mathrm{c}, \mathrm{d})+\mathrm{e}+\mathrm{H}_{\mathrm{t}}+\mathrm{K}_{\mathrm{t}}\right.$ ) diurutkan bit-bit untuk putaran 0 (round 0) tersebut :

$$
\begin{aligned}
\operatorname{CLS} 5(\mathrm{a}) & =11101000101001000110000000101100 \\
\mathrm{ft}(0)(\mathrm{b}, \mathrm{c}, \mathrm{d}) & =10011000101110101101110011111110 \\
\mathrm{ei}-1=\mathrm{e} 0= & 11000011110100101110000111110000 \\
\mathrm{Ht}=\mathrm{H} 0= & 00111010010000110011110001000001 \\
\mathrm{Kt} \leq \mathrm{t} \leq 19= & 01011010100000100111100110011001 \\
\hline \text { XORXOR } & =11010011000011010001100011100010
\end{aligned}
$$

Maka a' =11010011000011010001100011100010

$$
=\mathrm{D} 30 \mathrm{D} 18 \mathrm{E} 2
$$

Hasil di atas dijadikan nilai a', dan diurutkan dengan b', c', d', dan e'untuk putaran ke 1 dengan ketentuan : $a_{0}$ jadi b' atau $b_{1}$ $\mathrm{b}_{0}$ rotasi 10 kali $\left(\mathrm{CLS}_{10}\right)$ menjadi c' atau $\mathrm{c}_{1}$ $\mathrm{c}_{0}$ menjadi d' atau $\mathrm{d}_{1}$ $\mathrm{d}_{0}$ menjadi e' atau $\mathrm{e}_{1}$ $\mathrm{e}_{0}$ yang mengalami operasi dasar MGR menjadi a' atau al hasil tersebut dijadikan sebagai $t_{0}$ dan untuk CLS $_{10}($ b) yaitu rotasi b sebanyak 10 kali bit kanan ke kiri berurutan :

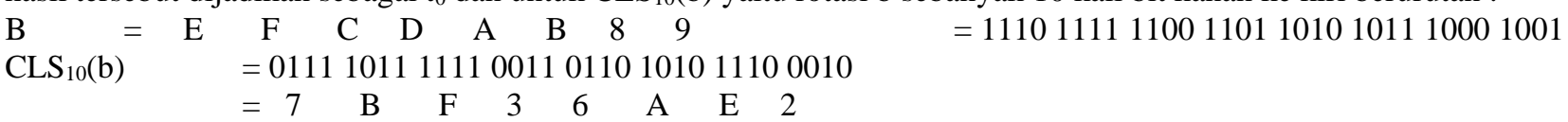

Tabel 2. Hasil $t_{0}$ berisi $a_{1}, b_{1}, c_{1}, d_{1}$, dan $e_{1}$

\begin{tabular}{lllll}
\hline $\mathrm{a}_{1}$ & $\mathrm{~b}_{1}$ & $\mathrm{c}_{1}$ & $\mathrm{~d}_{1}$ & $\mathrm{e}_{1}$ \\
$\mathrm{D} 30 \mathrm{D} 18 \mathrm{E} 2$ & 67452301 & 7BF36AE2 & 98BADCFE & 10325476 \\
\hline
\end{tabular}

$\mathrm{t}_{0}=\mathrm{D} 30 \mathrm{D} 18 \mathrm{E} 267452301$ 7BF36AE2 98BADCFE 10325476

Dan selanjutnya untuk mengerjakan $\mathrm{t} 1$ yaitu :

$a_{1}$ jadi b' atau $b_{2}$

\begin{tabular}{|c|c|c|c|c|c|}
\hline Round & A & B & $\mathrm{C}$ & $\mathrm{D}$ & $\mathrm{E}$ \\
\hline $\mathrm{t}_{0}$ & D30D18E2 & 67452301 & 7BF36AE2 & 98BADCFE & 10325476 \\
\hline$t_{1}$ & $8320637 \mathrm{E}$ & D94D24A1 & 8921A820 & 7B832F82 & 98BADCFE \\
\hline $\mathrm{t}_{2}$ & 98BADCFE & 8320837E & 20A8B802 & 8921A820 & 7B832F82 \\
\hline$t_{3}$ & 27EAF11B & 98BADCFE & 222A1A2B & 20A8B802 & $8921 \mathrm{~A} 820$ \\
\hline $\mathrm{t}_{4}$ & 28441228 & 27EAF11B & 28A8A322 & $222 \mathrm{~A} 1 \mathrm{~A} 2 \mathrm{~B}$ & $20 \mathrm{~A} 8 \mathrm{~B} 802$ \\
\hline$t_{5}$ & 38272170 & 28441228 & $837238 \mathrm{~A} 2$ & 28A8A322 & $222 \mathrm{~A} 1 \mathrm{~A} 2 \mathrm{~B}$ \\
\hline$t_{6}$ & 32383021 & 38272170 & B3AF2277 & $837238 \mathrm{~A} 2$ & 28A8A322 \\
\hline$t_{7}$ & 9AF2072A & 32383021 & 0A179290 & B3AF2277 & $837238 \mathrm{~A} 2$ \\
\hline$t_{8}$ & AB2F8328 & 9AF2072A & 7EAAF230 & 0A179290 & B3AF2277 \\
\hline$t_{9}$ & 83899929 & AB2F8328 & $27 F 30991$ & 7EAAF230 & $0 \mathrm{~A} 179290$ \\
\hline $\mathrm{t}_{10}$ & 8B2F9AF9 & 83899929 & $122 \mathrm{FB} 82 \mathrm{~F}$ & 27F30991 & 7EAAF230 \\
\hline$t_{11}$ & $2399991 \mathrm{~A}$ & 8B2F9AF9 & 202A78AF & $122 \mathrm{FB} 82 \mathrm{~F}$ & 27F30991 \\
\hline$t_{12}$ & A207B7EA & $2399991 \mathrm{~A}$ & 7AF2F7F2 & 202A78AF & $122 \mathrm{FB} 82 \mathrm{~F}$ \\
\hline$t_{13}$ & 912AF298 & A207B7EA & 99222389 & 7AF2F7F2 & $202 \mathrm{~A} 78 \mathrm{AF}$ \\
\hline $\mathrm{t}_{14}$ & 192BAF77 & 912AF298 & 19999232 & 99222389 & 7AF2F7F2 \\
\hline $\mathrm{t}_{15}$ & 20B7E228 & 192BAF77 & 24EF32F8 & 19999232 & 99222389 \\
\hline $\mathrm{t}_{16}$ & A892AF23 & 20B7E228 & 228F8B92 & $24 \mathrm{EF} 32 \mathrm{~F} 8$ & 19999232 \\
\hline $\mathrm{t}_{17}$ & $82 \mathrm{FF} 2728$ & A892AF23 & 28220AFB & 228F8B92 & 24EF32F8 \\
\hline $\mathrm{t}_{18}$ & 22299012 & $82 \mathrm{FF} 2728$ & 23179208 & 28220AFB & 228F8B92 \\
\hline $\mathrm{t}_{19}$ & 829AF272 & 22299012 & $2 \mathrm{~F} 0 \mathrm{~F} 322 \mathrm{~F}$ & 23179208 & 28220AFB \\
\hline $\mathrm{t}_{20}$ & 1F37B02F & 829AF272 & 77192A07 & $2 \mathrm{~F} 0 \mathrm{~F} 322 \mathrm{~F}$ & 23179208 \\
\hline $\mathrm{t}_{21}$ & 33F23B82 & 1F37B02F & 782787AF & 77192A07 & $2 \mathrm{~F} 0 \mathrm{~F} 322 \mathrm{~F}$ \\
\hline $\mathrm{t}_{22}$ & 21283A82 & 33F23B82 & 82828232 & 782787AF & 77192A07 \\
\hline $\mathrm{t}_{23}$ & 284E9122 & 21283A82 & 02899991 & 82828232 & 782787AF \\
\hline $\mathrm{t}_{24}$ & 27827222 & 284E9122 & A17F0221 & 02899991 & 82828232 \\
\hline $\mathrm{t}_{25}$ & A8A13B17 & 27827222 & 7AF072AB & $\mathrm{A} 17 \mathrm{~F} 0221$ & 02899991 \\
\hline
\end{tabular}

$\mathrm{b}_{1}$ rotasi 10 kali $\left(\mathrm{CLS}_{10}\right)$ menjadi c' atau $\mathrm{c}_{2}$

$\mathrm{c}_{1}$ menjadi d' atau $\mathrm{d}_{2}$

$\mathrm{d}_{1}$ menjadi e' atau $\mathrm{e}_{2}$

$\mathrm{e}_{1}$ yang mengalami operasi dasar MGR menjadi a' atau a2

Proses untuk $\mathrm{t}_{1}$ hingga $\mathrm{t}_{96}$ sangat panjang, disini langsung dibuat hasil $\mathrm{t}$ keseluruhan.

Tabel 3. Hasil a, b, c, d, dan e untuk $\mathrm{t}_{0}$ hingga $\mathrm{t}_{96}$ 
TIN: Terapan Informatika Nusantara

Vol 2, No 8, Januari 2022, Hal 492-500

ISSN 2722-7987 (Media Online)

Website https://ejurnal.seminar-id.com/index.php/tin

DOI 10.47065/tin.v2i8.1029

\begin{tabular}{|c|c|c|c|c|c|}
\hline Round & A & B & $\mathrm{C}$ & D & $\mathrm{E}$ \\
\hline $\mathrm{t}_{26}$ & B83AFB28 & A8A13B17 & B1289201 & 7AF072AB & A17F0221 \\
\hline $\mathrm{t}_{27}$ & AFF8A297 & B83AFB28 & 1210AAF9 & B1289201 & 7AF072AB \\
\hline $\mathrm{t}_{28}$ & 8370B828 & AFF8A297 & 2AF27899 & 1210AAF9 & B1289201 \\
\hline $\mathrm{t}_{29}$ & $2 \mathrm{AFB} 17 \mathrm{~F} 2$ & 8370 B 828 & 22FF1328 & 2AF27899 & 1210AAF9 \\
\hline $\mathrm{t}_{30}$ & 1227BA07 & 2AFB17F2 & F02222AB & $22 \mathrm{FF} 1328$ & 2AF27899 \\
\hline$t_{31}$ & 3B8A8233 & 1227BA07 & 717AFB27 & F02222AB & $22 \mathrm{FF} 1328$ \\
\hline $\mathrm{t}_{32}$ & 0A28FFF0 & 3B8A8233 & $2 \mathrm{~A} 328201$ & 717AFB27 & F02222AB \\
\hline$t_{33}$ & 2208B211 & 0A28FFF0 & 2AF11742 & 2A328201 & 717AFB27 \\
\hline $\mathrm{t}_{34}$ & $21792 \mathrm{~F} 2 \mathrm{~A}$ & 2208B211 & AF1B8F82 & $2 \mathrm{AF} 11742$ & 2A328201 \\
\hline$t_{35}$ & 22BBB $02 \mathrm{~B}$ & $21792 \mathrm{~F} 2 \mathrm{~A}$ & AB03F80A & AF1B8F82 & 2AF11742 \\
\hline $\mathrm{t}_{36}$ & 0AF19928 & 22BBB02B & 08991FB8 & AB03F80A & AF1B8F82 \\
\hline$t_{37}$ & 22239738 & 0AF19928 & 202AF232 & 08991FB8 & AB03F80A \\
\hline $\mathrm{t}_{38}$ & 42982A08 & 22239738 & 0324E782 & 202AF232 & 08991FB8 \\
\hline$t_{39}$ & $322 \mathrm{AF} 2 \mathrm{BF}$ & 42982A08 & 20991208 & 0324E782 & 202AF232 \\
\hline $\mathrm{t}_{40}$ & 82872828 & $322 \mathrm{AF} 2 \mathrm{BF}$ & 83221901 & 20991208 & 0324E782 \\
\hline $\mathrm{t}_{41}$ & $97 \mathrm{~F} 00220$ & 82872828 & $82 B 78728$ & 83221901 & 20991208 \\
\hline$t_{42}$ & 7AF93228 & 97F00220 & AF2120B7 & $82 \mathrm{~B} 78728$ & 83221901 \\
\hline $\mathrm{t}_{43}$ & AF1B1FF8 & 7AF93228 & 22028387 & $\mathrm{AF} 2120 \mathrm{~B} 7$ & $82 \mathrm{~B} 78728$ \\
\hline $\mathrm{t}_{44}$ & A082AF09 & AF1B1FF8 & AF224201 & 22028387 & $\mathrm{AF} 2120 \mathrm{~B} 7$ \\
\hline $\mathrm{t}_{45}$ & 12899992 & A082AF09 & $8 \mathrm{~B} 8222 \mathrm{FB}$ & AF224201 & 22028387 \\
\hline $\mathrm{t}_{46}$ & F01B8A22 & 12899992 & $8032 F 382$ & $8 \mathrm{~B} 8222 \mathrm{FB}$ & AF224201 \\
\hline $\mathrm{t}_{47}$ & B8F2022F & F01B8A22 & 871A7872 & $8032 \mathrm{~F} 382$ & $8 \mathrm{~B} 8222 \mathrm{FB}$ \\
\hline $\mathrm{t}_{48}$ & BF839337 & B8F2022F & 2802AF1B & 871A7872 & 8032 F382 \\
\hline $\mathrm{t}_{49}$ & 12073128 & BF839337 & F8FBA0B2 & 2802AF1B & 871A7872 \\
\hline $\mathrm{t}_{50}$ & 2A12B228 & 12073128 & AFB28422 & F8FBA0B2 & 2802AF1B \\
\hline $\mathrm{t}_{51}$ & 38A7F7E2 & 2A12B228 & 4EAF2271 & AFB28422 & F8FBA0B2 \\
\hline $\mathrm{t}_{52}$ & 8990A37E & 38A7F7E2 & 320722B3 & 4EAF2271 & AFB28422 \\
\hline $\mathrm{t}_{53}$ & 2789AF28 & 8990A37E & AF199B89 & 320722B3 & 4EAF2271 \\
\hline $\mathrm{t}_{54}$ & 7B71207E & 2789AF28 & 792A102B & AF199B89 & 320722B3 \\
\hline $\mathrm{t}_{55}$ & AF2A82F8 & 7B71207E & 098F7272 & 792A102B & AF199B89 \\
\hline $\mathrm{t}_{56}$ & $28 \mathrm{~A} 20938$ & AF2A82F8 & AF2277EB & 098F7272 & $792 \mathrm{~A} 102 \mathrm{~B}$ \\
\hline$t_{57}$ & 22228990 & 28A20938 & 273299FB & AF2277EB & 098F7272 \\
\hline $\mathrm{t}_{58}$ & 09278992 & 22228990 & $821992 \mathrm{~A} 8$ & 273299FB & AF2277EB \\
\hline $\mathrm{t}_{59}$ & $3 \mathrm{AF} 22 \mathrm{AFF}$ & 09278992 & 3998B82A & $821992 \mathrm{~A} 8$ & $273299 \mathrm{FB}$ \\
\hline $\mathrm{t}_{60}$ & $278221 \mathrm{~A} 7$ & $3 \mathrm{AF} 22 \mathrm{AFF}$ & 427AF178 & 3998B82A & 821992A8 \\
\hline $\mathrm{t}_{61}$ & 8A8292B2 & $278221 \mathrm{~A} 7$ & AF2AB792 & 427AF178 & 3998B82A \\
\hline$t_{62}$ & B7E2020B & 8A8292B2 & $\mathrm{AF} 28 \mathrm{~B} 0 \mathrm{AF}$ & AF2AB792 & 427AF178 \\
\hline $\mathrm{t}_{63}$ & 2B2129AF & B7E2020B & 98232722 & $\mathrm{AF} 28 \mathrm{~B} 0 \mathrm{AF}$ & AF2AB792 \\
\hline $\mathrm{t}_{64}$ & $1928 F 7 F 2$ & 2B2129AF & 829BBA82 & 98232722 & $\mathrm{AF} 28 \mathrm{~B} 0 \mathrm{AF}$ \\
\hline $\mathrm{t}_{65}$ & 10128999 & 1928F7F2 & $8 \mathrm{~F} 287278$ & 829BBA82 & 98232722 \\
\hline $\mathrm{t}_{66}$ & 023282BA & 10128999 & 0277898B & $8 \mathrm{~F} 287278$ & $829 B B A 82$ \\
\hline $\mathrm{t}_{67}$ & 787EA22B & 023282BA & 4E089878 & 0277898B & $8 \mathrm{~F} 287278$ \\
\hline $\mathrm{t} 68$ & 99709320 & 787EA22B & 030202F2 & 4E089878 & 0277898B \\
\hline $\mathrm{t}_{69}$ & 38289922 & 99709320 & $283783 \mathrm{AF}$ & $030202 \mathrm{~F} 2$ & 4E089878 \\
\hline $\mathrm{t}_{70}$ & $2132 \mathrm{AF} 27$ & 38289922 & $12202 \mathrm{~A} 80$ & $283783 \mathrm{AF}$ & $030202 \mathrm{~F} 2$ \\
\hline $\mathrm{t}_{71}$ & 39AF9287 & AF 27 & AF292230 & $12202 \mathrm{~A} 80$ & $283783 \mathrm{AF}$ \\
\hline $\mathrm{t}_{72}$ & $82 \mathrm{~B} 4228 \mathrm{~A}$ & 39AF9287 & $807 \mathrm{E} 7831$ & AF292230 & $12202 \mathrm{~A} 80$ \\
\hline $\mathrm{t}_{73}$ & 793828 & $82 \mathrm{~B} 4228 \mathrm{~A}$ & 28212779 & 807 E7831 & AF292230 \\
\hline $\mathrm{t}_{74}$ & 89972897 & 11793828 & 3В7Е0В79 & 28212779 & 807E7831 \\
\hline $\mathrm{t}_{75}$ & $23202 \mathrm{FB} 7$ & 89972897 & 2AA1782B & 3В7E0B79 & 28212779 \\
\hline $\mathrm{t}_{76}$ & F079B729 & $23202 \mathrm{FB} 7$ & 27B92F 28 & $2 \mathrm{AA} 1782 \mathrm{~B}$ & 3В7Е0В79 \\
\hline $\mathrm{t}_{77}$ & 82022122 & F079B729 & 2AF282F2 & 27B92F28 & 2AA1782B \\
\hline $\mathrm{t}_{78}$ & 87382AF1 & 82022122 & 28997E82 & 2AF282F2 & 27B92F 28 \\
\hline $\mathrm{t}_{79}$ & 428A1B38 & 87382AF1 & 2993 A 873 & 28997E82 & 2AF282F2 \\
\hline $\mathrm{t}_{80}$ & F01B8A22 & 12899992 & $8032 F 382$ & $8 \mathrm{~B} 8222 \mathrm{FB}$ & AF224201 \\
\hline $\mathrm{t}_{81}$ & B8F2022F & F01B8A22 & 871A7872 & $8032 F 382$ & $8 \mathrm{~B} 8222 \mathrm{FB}$ \\
\hline $\mathrm{t}_{82}$ & BF839337 & B8F2022F & 2802AF1B & 871A7872 & $8032 \mathrm{~F} 382$ \\
\hline $\mathrm{t}_{83}$ & 12073128 & BF839337 & F8FBA0B2 & 2802AF1B & 871A7872 \\
\hline $\mathrm{t}_{84}$ & 2A12B228 & 12073128 & AFB28422 & F8FBA0B2 & 2802AF1B \\
\hline t85 & 38A7F7E2 & 2A12B228 & 4EAF2271 & AFB28422 & F8FBA0B2 \\
\hline $\mathrm{t}_{86}$ & 8990A37E & 38A7F7E2 & 320722B3 & 4EAF2271 & AFB28422 \\
\hline t87 & 2789AF28 & 8990A37E & AF199B89 & 320722B3 & 4EAF2271 \\
\hline t88 & 7B71207E & 2789AF28 & 792A102B & AF199B89 & $320722 \mathrm{~B} 3$ \\
\hline $\mathrm{t}_{89}$ & AF2A82F8 & 7B71207E & 098F7272 & 792A102B & AF199B89 \\
\hline$t_{90}$ & 28A20938 & $\mathrm{AF} 2 \mathrm{~A} 82 \mathrm{~F} 8$ & AF2277EB & $098 F 7272$ & 792A102B \\
\hline$t_{91}$ & 22228990 & 28A20938 & 273299FB & AF2277EB & 098F7272 \\
\hline$t_{92}$ & 09278992 & 22228990 & 821992A8 & $273299 \mathrm{FB}$ & AF2277EB \\
\hline
\end{tabular}




\section{TIN: Terapan Informatika Nusantara}

Vol 2, No 8, Januari 2022, Hal 492-500

ISSN 2722-7987 (Media Online)

Website https://ejurnal.seminar-id.com/index.php/tin

DOI 10.47065/tin.v2i8.1029

\begin{tabular}{cccccc}
\hline Round & A & B & C & D & E \\
\hline t $_{93}$ & 3AF22AFF & 09278992 & 3998B82A & 821992A8 & 273299FB \\
t94 $_{94}$ & 278221A7 & 3AF22AFF & 427AF178 & 3998B82A & 821992A8 \\
t $_{95}$ & 8A8292B2 & 278221A7 & AF2AB792 & 427AF178 & 3998B82A \\
t96 $_{96}$ & B7E2020B & 8A8292B2 & AF28B0AF & AF2AB792 & 427AF178 \\
\hline
\end{tabular}

Selanjutnya setelah didapatkan a, b, c, d, dan e untuk t96, maka nilai t96 digunakan untuk mendapatkan cipher atau biasa disebut digest dalam MGR dengan cara di XOR dengan nilai a, b, c, d, dan e awal (penyangga).

$\mathrm{H}_{\mathrm{i}}=\mathrm{a}_{0}+\mathrm{a}_{\mathrm{n}}$

$\mathrm{H}_{0} \quad=67452301+428 \mathrm{~A} 1 \mathrm{~B} 38$

01100111010001010010001100000001

$=\frac{01000010100010100001101100111000}{00100101110011110011100000111001}$

$=\frac{010000101001110011110011100000111001}{00100101}$

$=25 \mathrm{CF} 3839$

$\mathrm{H}_{1} \quad=\mathrm{EFCDAB} 89+87382 \mathrm{AF} 1$

11101111110011011010101110001001

$-10000111001110000010101011110001$

$=\frac{1101000111101011000000101111000}{0100}$

$=68 \mathrm{~F} 58178$

$\mathrm{H}_{2} \quad=98 \mathrm{BADCFE}+2993 \mathrm{~A} 873$

10011000101110101101110011111110

$=\frac{00101001100100111010100001110011}{10110001001010010111010010001101}$

$=\mathrm{B} 129748 \mathrm{D}$

$\mathrm{H}_{3} \quad=10325476+28997 \mathrm{E} 82$

00010000001100100101010001110101

$=\frac{00101000100110010111111010000010}{00111000101010110010101011110111}$

$=38 \mathrm{AB} 2 \mathrm{AF} 7$

$\mathrm{H}_{4}=\mathrm{C} 3 \mathrm{D} 2 \mathrm{E} 1 \mathrm{~F} 0+2 \mathrm{AF} 282 \mathrm{~F} 2$

11000011110100101110000111110000

$=\frac{00101010111100101000001011110010}{11101001001000000110001100000010}$

$=\mathrm{D} 9206302$

Concate h0, h1, h2, h3, dan h4. Hasil concate sebanyak 20 karakter tersebut menjadi cipherteks atau disebut message digest.

\section{KESIMPULAN}

Berdasarkan pembahasan yang dilakukan dapat disimpulkan aplikasi dapat menampilkan proses mendeteksi keaslian citra menggunakan matlab. Mendeteksi keaslian citra menggunakan format jpg dan bmp. Untuk melakukan resolusi pengujian menggunakan nilai pixel 6x6.

\section{REFERENCES}

[1] Bussi, K. et al. (2015) 'MGR Hash Function', pp. 1-16.

[2] abdul kadir dan adhi susanto (2013) 'teori dan aplikasi pengolahan citra digital', in yogyakarta : andi.

[3] Putra, D. (2010) Pengolahan Citra Digital. Edited by Westriningsi. Yokyakarta: ANDI.

[4] Haraphap (2014) pengertian analisa.

[5] Kriptografi, K. K. and Transposition, C. (2017) 'ANALISA DAN IMPLEMENTASI KRIPTOGRAFI PADA PESAN RAHASIA', 3(1), pp. 1-11. 